\title{
Format Rancangan Sistem Informasi untuk Database Aspirasi Himpunan
}

\author{
Muhammad Fadhil Rafif \\ Telkom University; \\ Email: fadhilrafif@telkomuniversity.ac.id
}

\begin{abstract}
Sistem aplikasi ini ialah sebuah sistem yang membantu para pelaku organisasi untuk mengolah segala aspirasi yang dilontarkan semua entitas, hal ini memudahkan organisasi/himpunan tersebut dalam menampung segala ide dan menambah variabel pengambilan keputusan.
\end{abstract}

Keywords: Aspirasi

Paper ini akan dipublikasikan di osf.io [1] menggunakan format standard perancangan sistem informasi [2]

\section{Introduction}

1.1. Business case

Project Definition: Ide rancangan sistem informasi ini didasari oleh banyaknya aspirasi dari seluruh entitas untuk kemajuan himpunan namun tidak ada sistem yang dapat mengolah aspirasi tersebut dengan baik dan maksimal, maka dari itu diperlukan sebuah sistem informasi yang mengolah dan mengarah aspirasi tersebut ke ruang lingkup yang lebih jelas.

Project Objective: Sistem Informasi ini bertujuan ntuk mengolah dan mengarah segala aspirasi ke ruang lingkup himpunan dengan jelas dan terarah

System Definition: Sistem yang dibutuhkan yaitu untuk mengarahkan isi aspirasi dari aspirator kepada lingkup himpunan yang bertanggung jawab atas isi aspirasi tersebut.

\subsection{System Requirement}

System Function: Tujuan sistem informasi ini ialah agar aspirasi yang dilayangkan oleh aspirator lebih terarah dan sesuai dengan kapasitas yang ingin dicakup.

System Feature:

1. Dapat melihat tampilan laman sistem

2. Dapat mempermudah entitas dalam menyampaikan aspirasi

3. Terdapat informasi terkait dengan himpunan

4. Dapat melihat aspirasi yang masuk terkait himpunan

Acceptance Criteria:

1. Sistem ini membutuhkan koneksi Internet

2. Setiap pengguna perlu registrasi dan mempunyai akun agar dapat menjadi aspirator

3. Penggunaan akun bersifat individu yang disertai nomor induk dan tidak dapat digandakan

4. Seluruh data terkait pengguna yang sudah terdaftar akan tersimpan dalam database

5. Pengguna perlu melakukan login untuk menggunakan fitur pada laman sistem

\section{Penjelasan SIngkat Terkait Metode}

Metode yang digunakan ialah pengumpulan data yang dibutuhkan untuk menjalankan sistem informasi. 


\section{Proses Perhitungan}

3.1.System Design

Berikut merupakan kolom yang perlu diisi oleh aspirator

Tabel 2. Contoh Penlisan Tabel

\begin{tabular}{ccc}
\hline No. & Data_Aspirasi & Isi Data \\
\hline 1 & Kode_Aspirasi & 001 \\
2 & Nama_Entitas & Wawan Gunawan \\
3 & Nomor_Induk & 12011 xxxxx \\
4 & Tanggal_Aspirasi & $31 / 05 / 2020$ \\
5 & Isi_Aspirasi & xxx \\
\hline
\end{tabular}

3.2. Data Flow Diagram (DFD)

Terdapat beberapa level dalam pembuatan DFD, semakin besar level maka akan semakin kompleks informasi yang digambarkan.

a) Level 0

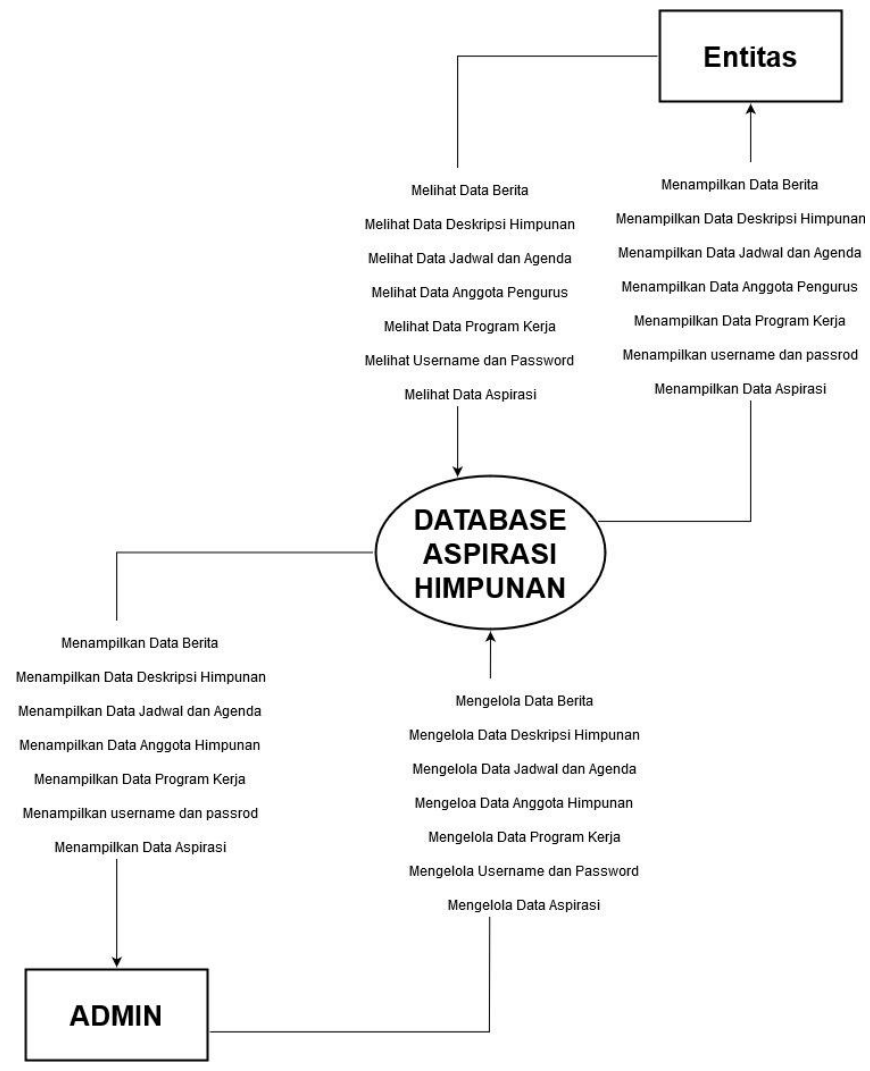

Figure 1 Gambar Data Flow Diagram

b) Level 1 


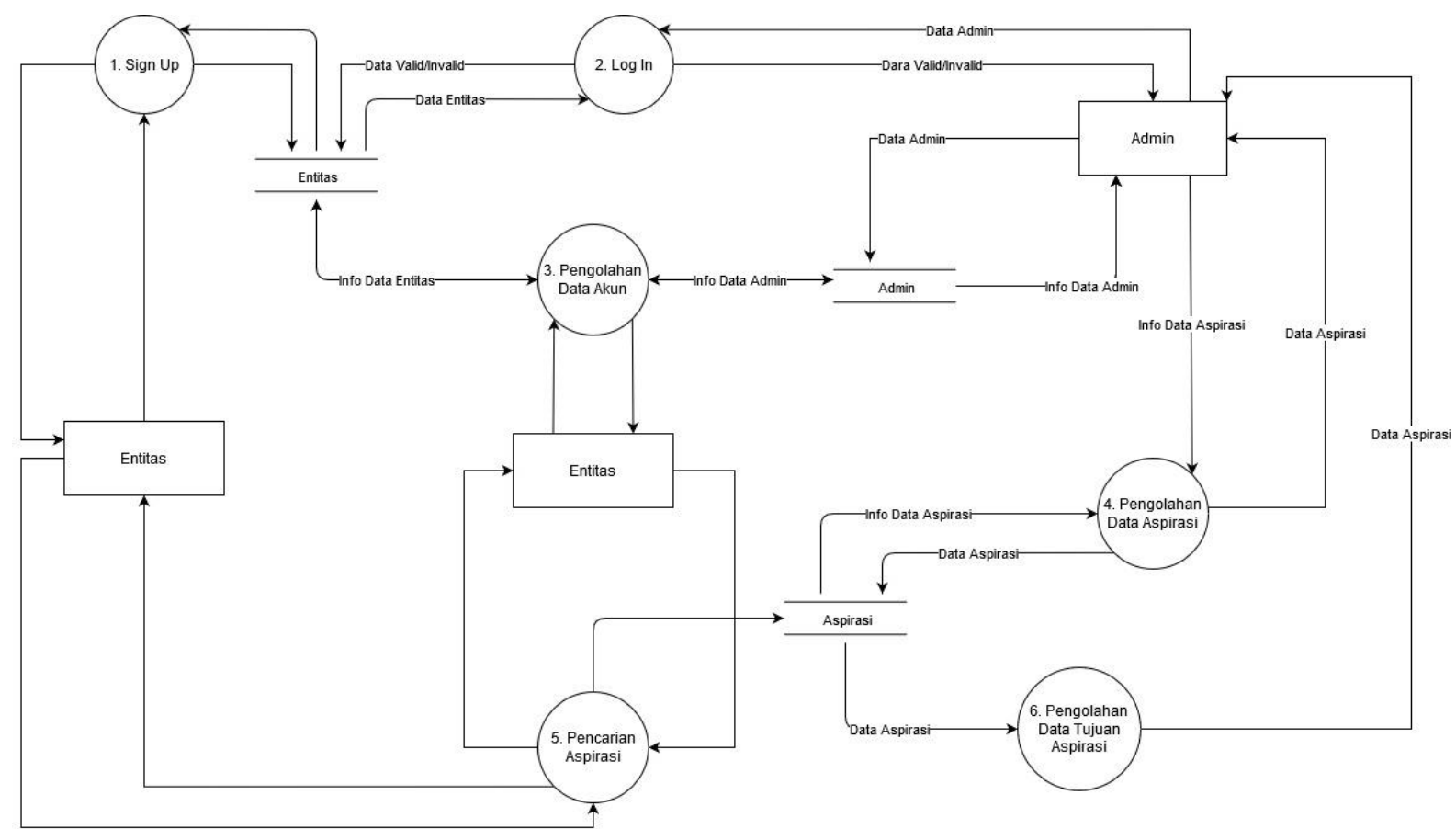

c) Level 2

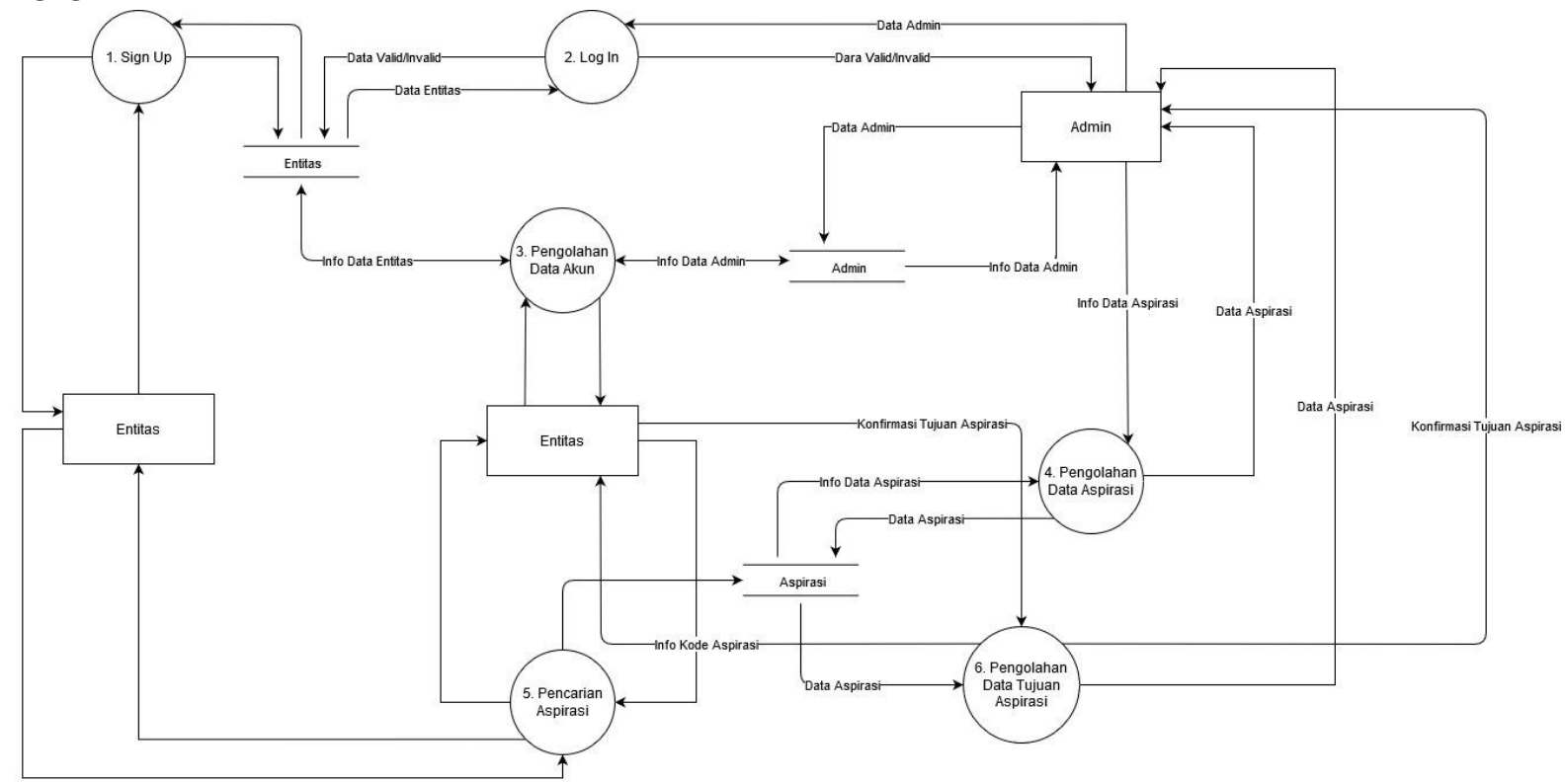

3.3. Entity Relationship Diagram (ERD) 


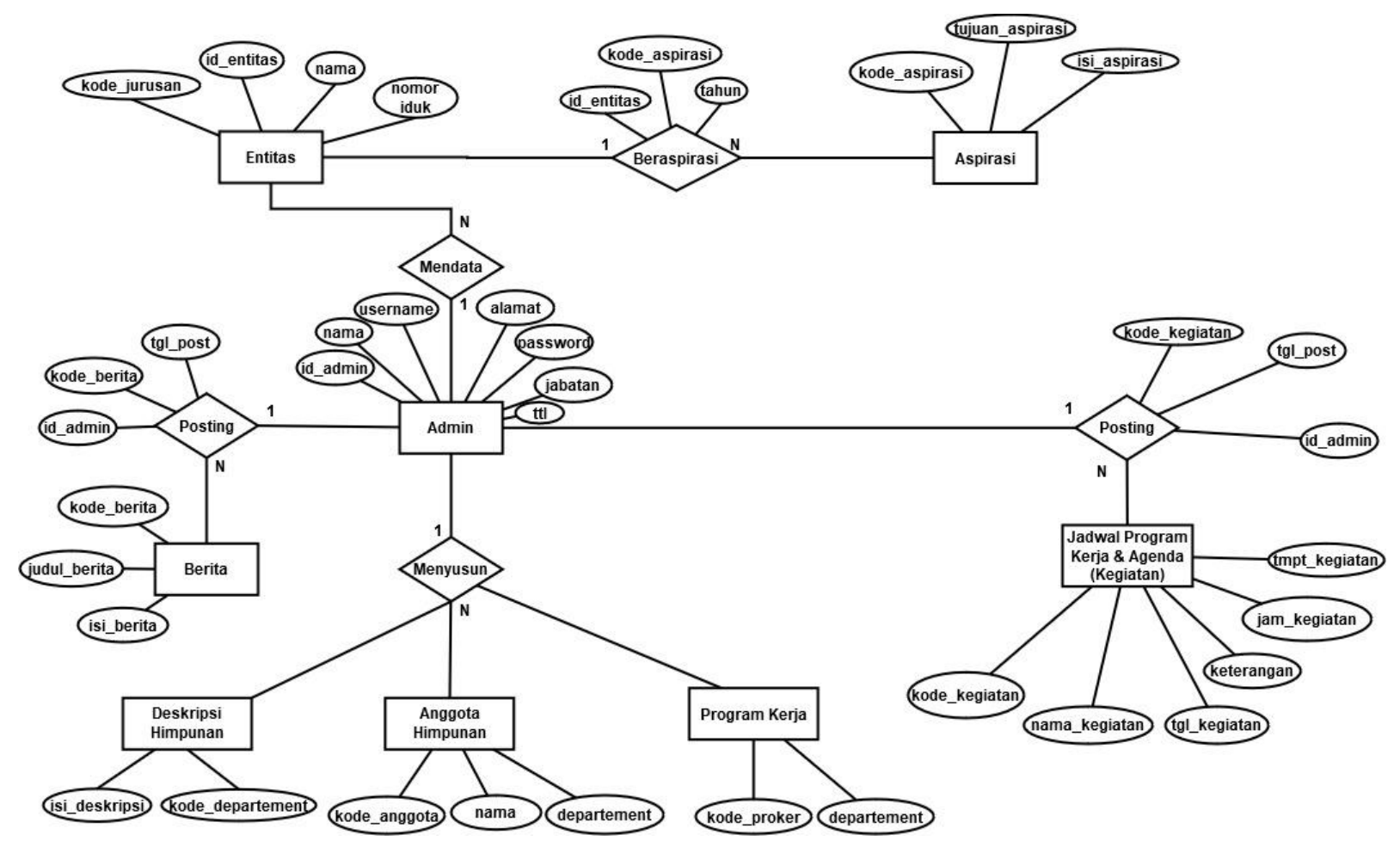

Figure 4 Gambar ERD

Entity Relationship Diagram adalah sebuah model penggambaran dalam sistem untuk menjelaskan berbagai macama hubungan antara data dalam sistem basis data terkait berdasarkan dengan objekobjek dasar data yang mempunyai hubungan atau relasi dengan data yang lainnya.

\subsection{Database Design}

Data Objects and File and Database Structures

\subsection{Use Case Diagram}

1. Use Case Diagram Sistem Entitas

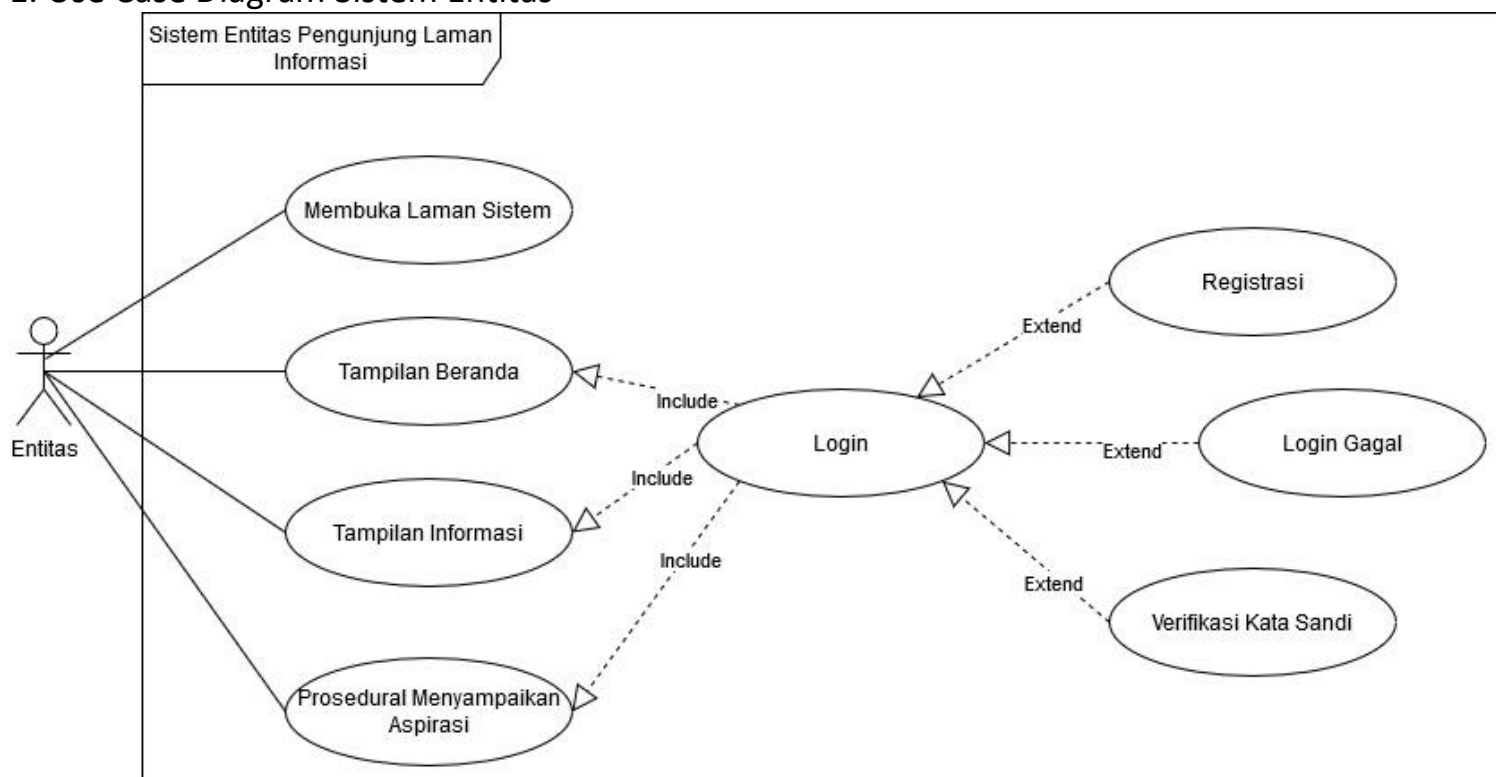




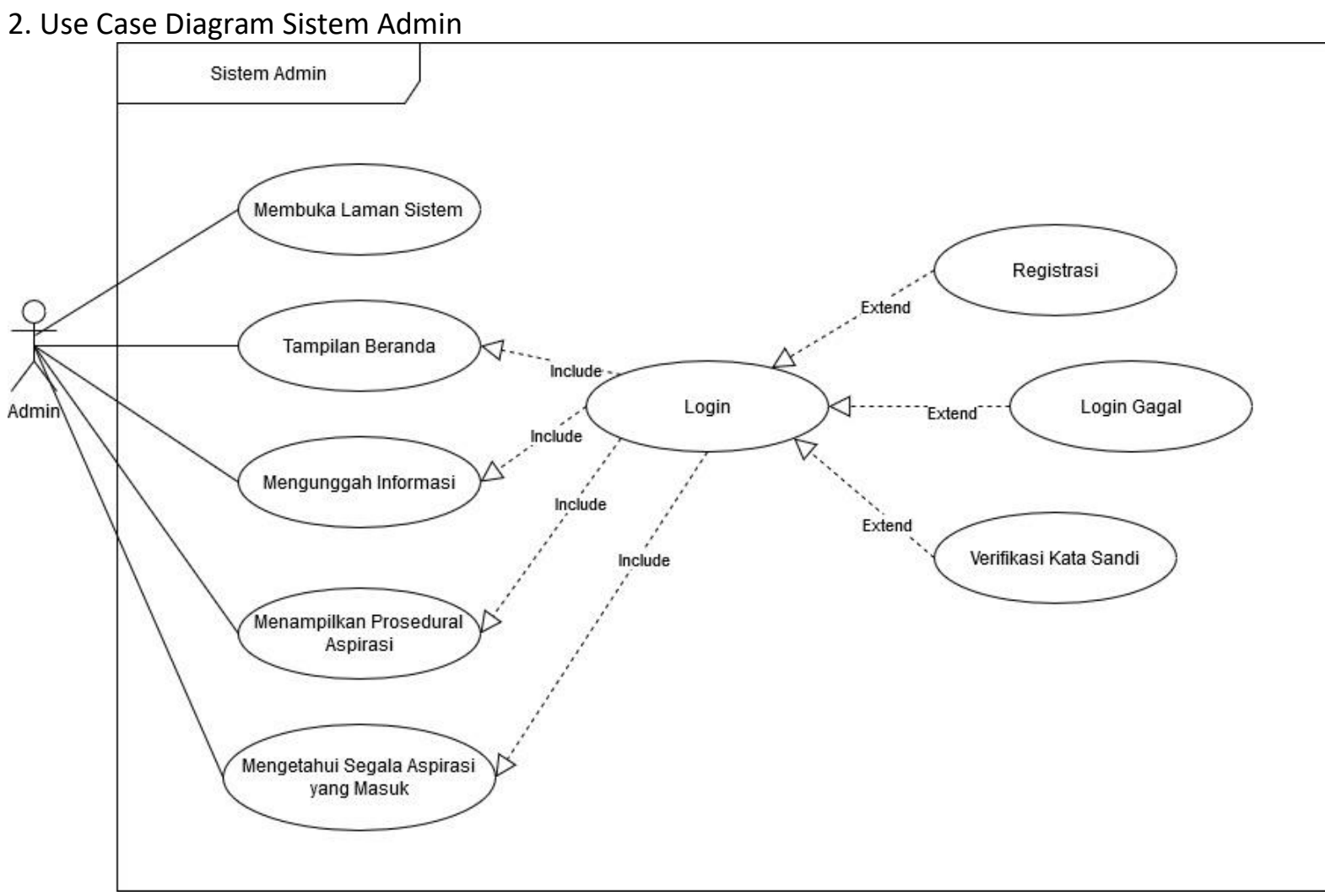

Figure 5 Gambar Use Case Diagram

\subsection{Activity Diagram}

1. Activity Diagram Regustrasi 


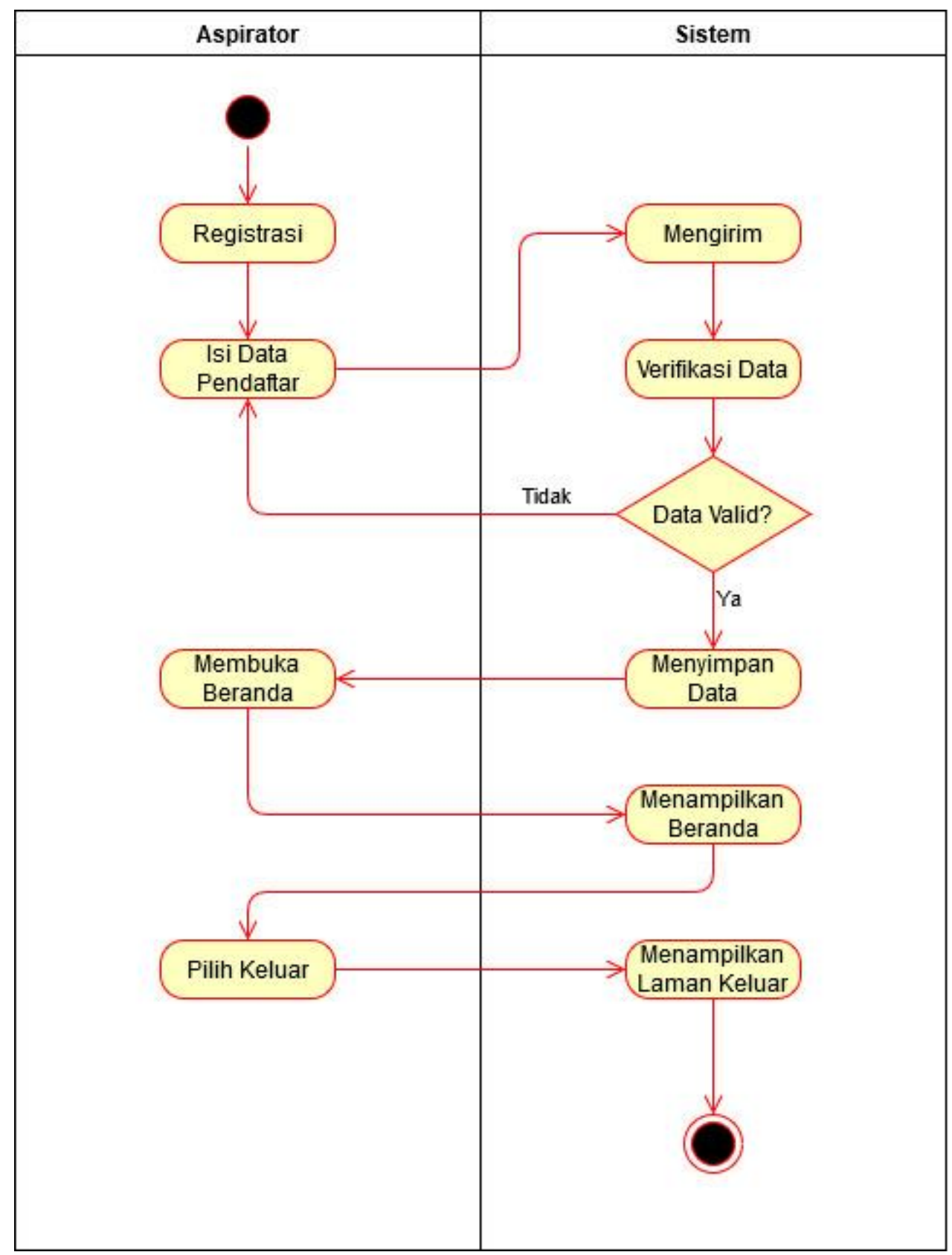

Figure 6 Gambar Activity Diagram

2. Activity Diagram Aspirator 


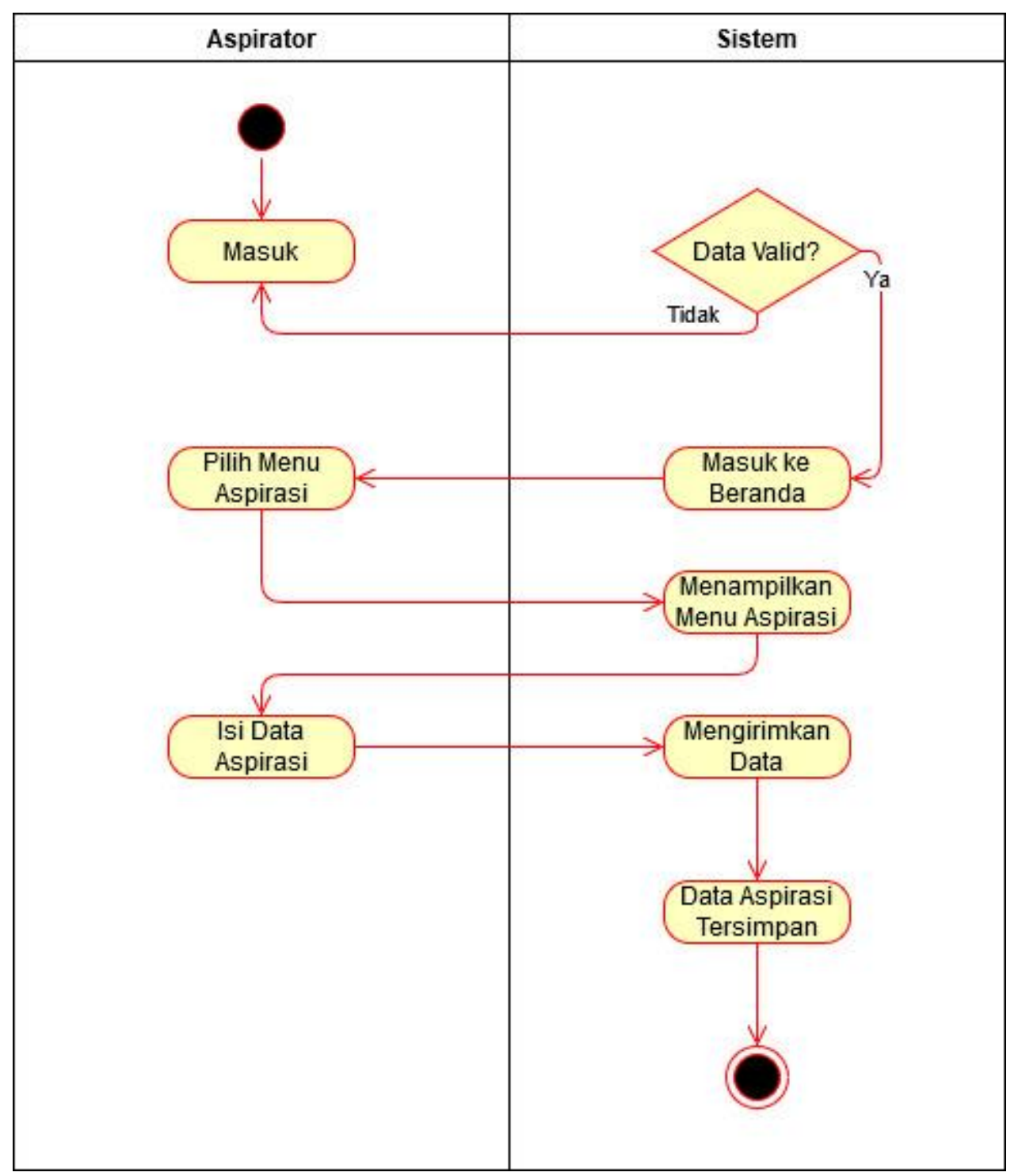

\subsection{Sequence Diagram}

Tuliskan penjelasan di sini (salah satu function)

3.8 Interface Design

-Interface Architecture, Interface Detailed Design (with screenshots), Provide the screenshots of the system 


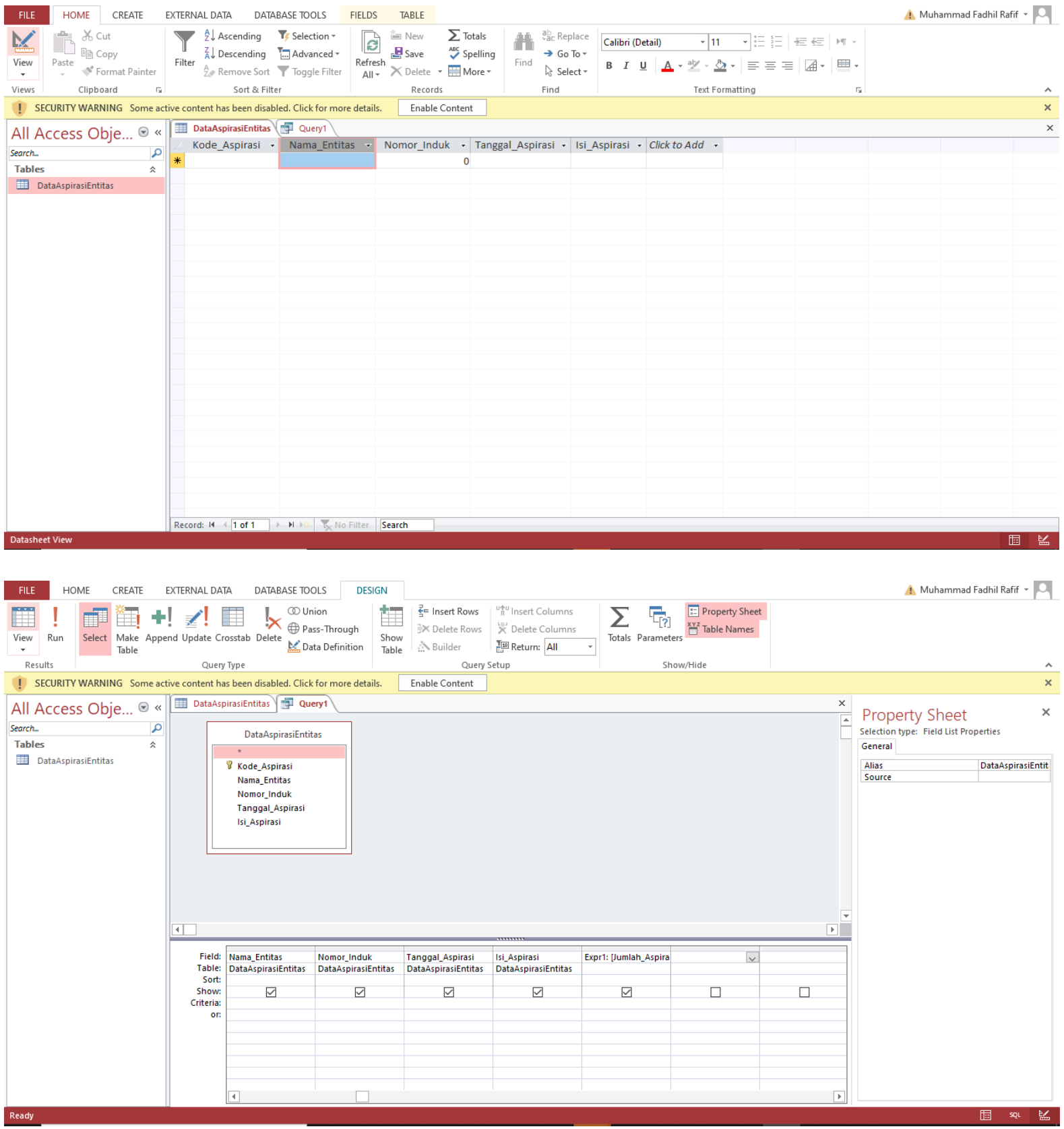

Figure 8 Gambar

\subsection{Source Code}

Tuliskan penjelasan di sini

\section{Penutup}

4.1 Kesimpulan

Sistem Informasi ini dioperasikan untuk proses penyampaian aspirasi secara terarah, hal ini membantu himpunan untuk mengetahui kebutuhan seluruh entitas yang bersinggungan langsung dengan kerja himpunan tersebut, sehingga terciptanya keterlibatan semua pihak dalam memajukan himpunan tersebut.

\subsection{Saran}

Sistem Informasi ini perlu bekerja sama langsung dengan pihak fakultas agar informasi yang disampaikan ke seluruh entitas merata dengan baik. 


\section{References}

[1] R. Aurachman, "Review Terhadap OSF.IO Sebagai Sarana Publikasi Preprint," OSF Preprints, 17 May 2020.

[2] R. Aurachman, "Kerangka Perancangan Sistem Informasi Sebagai Pembelajaran Mahasiswa Teknik Industri," osf.io, 52020.

\section{Additional}

[a] R. Aurachman, "Review Terhadap OSF.IO Sebagai Sarana Publikasi Preprint," OSF Preprints, 17 May 2020. doi:10.31219/osf.io/rvumx , Available: https://osf.io rvumx

[b] R. Aurachman, "Kerangka Perancangan Sistem Informasi Sebagai Pembelajaran Mahasiswa Teknik Industri," osf.io, doi:10.31219/osf.io/tmpen , 5 2020. Available: https://osf.io/tmpen 